\title{
Subacute toxicity study of an aqueous extract of dried leaves of Gymnosporia spinosa on albino rats
}

\author{
Amita R. Kubavat, Hetal D. Rajguru, Shahenaz M. Malek*
}

Department of Pharmacology, P.D.U. Medical College, Rajkot, Gujarat, India

Received: 02 December 2019

Revised: 15 December 2019

Accepted: 17 December 2019

\author{
*Correspondence: \\ Dr. Shahenaz M. Malek, \\ Email: dranwarfm@gmail.com
}

Copyright: ( ) the author(s), publisher and licensee Medip Academy. This is an open-access article distributed under the terms of the Creative Commons Attribution Non-Commercial License, which permits unrestricted non-commercial use, distribution, and reproduction in any medium, provided the original work is properly cited.

\begin{abstract}
Background: Leaves of Gymnosporia spinosa have been used by people for treatment of jaundice. Traditional herbal drugs are popular all over the world and it is presumed that herbal medicines have lesser or no side effects. This generalized belief and no information available regarding toxicity study of $G$. spinosa with search from limited available information prompted us to carry out work on subacute toxicity study of aqueous extract of dried leaves of G. spinosa.

Methods: Subacute toxicity study was carried out using aqueous extract of $G$. spinosa leaves. 30 rats of either sex were randomly divided in to 4 groups. First group received distilled water (control). Second, third and fourth groups received single daily dose of drug orally as 40,120 and $240 \mathrm{mg} / 100 \mathrm{~g}$ of body weight respectively for 3 weeks. Animals were observed for various parameters. After 21 days blood was collected for blood counts and biochemical parameters. Liver, lungs and kidney were subjected to histo-pathological studies.

Results: Throughout study there was no mortality in any group. Degenerative changes in the liver. Other organ does not show any changes. Analysis of biochemical data showed serum glutamic pyruvic transaminase and s. alkaline phosphatase levels were decreased. Serum bilirubine, blood urea and serum creatinine level were increased significantly.

Conclusions: The data showed that there was hepato-renal toxicity at higher dose level which is about 100x human therapeutic dose.
\end{abstract}

Keywords: Subacute toxicity, Aqueous extract, G. spinosa

\section{INTRODUCTION}

In spite of tremendous advancement in medical and pharmaceutical sciences and significant improvement in living condition of human beings, definitive treatment for liver diseases associated with hepatic cell damage is not available.

The drugs available in modern system of medicine provide only symptomatic relief. On the other hand, there are a number of plant drug that have been claimed to have curative effect and are used in management of various liver disorders, in the traditional or indigenous system of medicine and practiced throughout the world.

One of such herb Gymnosporia spinosa has been used for various disorders like it cures biliousness, purifies the blood, cures ulcer, piles; remove "kapha", inflammation, burning thirst and corneal opacity. ${ }^{1-3}$

Leaves of $G$. spinosa have been used by people living in Gujarat for treatment of liver disorders. Hepatoprotective 
activity of $G$. spinosa leaves has been studied. ${ }^{4}$ Antispasmodic effects were also reported with the crude plant extract..$^{5}$ Pharmacognosy of G. sporia spinosa leaves where studied at Gujarat Ayurved university. ${ }^{6}$

\section{Objectives}

Leaves of $G$. spinosa have been used by people for treatment of jaundice. Limited information is available regarding toxicity studies which prompted us to carry out this work.

\section{METHODS}

Drug: The plant material (leaves of G. spinosa) was collected in August-September 2001, from village area near Jamnagar and identification of plant has been done by Pharmacognosy Department of Ayrvedic University Jamnagar.

The shade dried leaves were grinded and passed through sieve. Then finally the aqueous extract of the leaves powder was prepared. Thus for $800 \mathrm{mg}$ dried leaves powder, $20 \mathrm{ml}$ of distilled water was used to prepare aqueous extract.

\section{Animals}

The Charles Foster albino rats of either sex were administered. All the rats were bred in the Pharmacology Department, M.P. Shah Medical College, Jamnagar and they were fed with standard pellet laboratory diet and ordinary tap water. The study was designed to evaluate subacute toxicity of the drug.

\section{Subacute toxicity study}

For evaluating subacute toxicity, Charles Foster albino rats of either sex were housed; four animals per cage for one week to acclimatized and were provided food and water ad - libitum. Then the rat were housed one per cage for 7 days for food training i.e. (they were provided food only for $6 \mathrm{hrs} / \mathrm{day})$ and rota-rod training. Then the rats were divided into 4 groups: (7, 9, 7 and 7 rats respectively) allocation was done in randomized fashion. Average food intake for three days was measured in all animals, before starting the experiment. First group received plain water only, and was used as control. Group 2,3 and 4 were treated orally with aq. extract of $G$. Spinosa $40 \mathrm{mg}, 120 \mathrm{mg}$ and $240 \mathrm{mg}$ per $100 \mathrm{~g}$ of the Body-weight single dose for 21 days respective. Selection of dose level in different groups were decided on the basis of human therapeutic dose is $800 \mathrm{mg} / 60 \mathrm{~kg}$ of body weight, so group 1 (low dose) 30 times, group 2 (intermediate dose) 90 times and group 3 (higher dose) 180 times of human therapeutic dose. ${ }^{7}$ The animals were observed on each day 3 animals from group 2 were kept on recovery period for 7 day; they were given food and water ad-libitum during recovery period.

\section{Parameters for observations}

Mortality of animals, motor activity, tremors, convulsions, posture, spasticity, opisthotonicity, ataxia, righting reflex, sensations, pilo-erection, ptosis, lacrimation, exopthalmos, salivation, diarrhoea, writhing, skin colour and respiratory rate, muscle coordination, pain reflex, daily food intake and body weight of animal were observed. Blood was drawn from each of the animal by cardiac puncture to determine: Haemoglobin, red blood cells count, white blood cells (WBC) count, blood urea, random blood glucose, serum creatinin, serum cholesterol and serum glutamic pyruvic transaminase (SGPT) (Blood chemistry was carried out in the Pathology Laboratory using semi auto analyser). Then the animals were sacrificed, their liver, lung \& kidney dissected out and their gross and histo pathological examinations were done by a pathologist who was not knowing the distribution of animal in study group and Control group. ${ }^{8,9}$

Muscle co-ordination was measured by rota-rod instrument.

Except 3 animals from group 2 all other animals were sacrificed for histopathology examination and haematology examination. After 21 days, remaining 3 animals from group- 2 were kept for recovery for 7 days i.e. drug administration was stopped in them and were provided food and water ad-libitum. After 7 days recovery period, these animals were sacrificed for detailed haematological, histopathology and post-mortem examination.

Data was analysed by using student "t" test (unpaired and paired) $p \leq 0.05$ was considered as statistically significant.

\section{RESULTS}

Sub-acute toxicity study of an aqueous extract of $G$. spinosa leaves (after 3 weeks).

There were no death of any animal in any of groups during the period of study hence it was not possible to establish $\mathrm{LD}_{50}$ in this series of experiments. In all treated group body weight is increased after the treatment. It is statistically significant in $40 \mathrm{mg} / 100 \mathrm{~g}$ dose and 120 $\mathrm{mg} / 100 \mathrm{~g}$ dose of drug.

Haemoglobin level was decreased in all three treated group in comparison of control group and statistically significant in $240 \mathrm{mg} / 100 \mathrm{~g}$ dose. And WBC count increased in treated groups.

Blood urea and creatinine increased. Serum creatinine was significantly increased in $240 \mathrm{mg} / 100 \mathrm{~g}$ and weight of kidney significantly reduces at $240 \mathrm{mg} / 100 \mathrm{~g}$.

Serum enzymes, shows tendency to decrease in SGPT levels in animals treated which are statistically not 
significant. We found that serum cholesterol level significantly increases at $40 \mathrm{mg} / 100 \mathrm{~g}$ and $240 \mathrm{mg} / 100 \mathrm{~g}$ dose (s. cholesterol increases at all doses).

There was a tendency to increase in s. bilirubin at all dose level, but statistically significant was shown at $40 \mathrm{mg} / 100$ $\mathrm{g}$ dose level in indirect $\mathrm{s}$. bilirubin.

There was a tendency to decrease in organ weight on continuous administration of higher doses of drug. Statistically significance was shown to decreased weight of the kidney in $240 \mathrm{mg} / 100 \mathrm{~g}$.

On histopathological examination revealed normal kidney and lung structure in all animals. Studies section of liver shows cloudy degenerative changes in all treated groups and in one animal of shows cloudy swelling with early fatty changes with a dose $240 \mathrm{mg} / 100 \mathrm{~g}$.

At the dose $120 \mathrm{mg} / 100 \mathrm{~g}$ falling rate were significantly decreased after first wk. At dose $240 \mathrm{mg} / 100 \mathrm{~g}$ falling rate were significantly decreased after first and second week.

In all three doses there were no apparent changes in motor activity measured weekly. No statistical test applied to it.

There were no apparent changes in second group of 3 animals after one week of recovery period.

Table 1: Effects of aqueous extract of $G$. spinosa on body weight of rats.

\begin{tabular}{|c|c|c|c|}
\hline \multirow{3}{*}{ Dose of drug } & \multirow{3}{*}{ No. of animal } & \multicolumn{2}{|c|}{ Animal weight (g) } \\
\hline & & Before drug & After drug \\
\hline & & Mean \pm SE & Mean \pm SE \\
\hline $40 \mathrm{mg} / 100 \mathrm{~g}$ & 6 & $173.6 \pm 5.32$ & $189.9 \pm 7.59^{* *}$ \\
\hline $120 \mathrm{mg} / 100 \mathrm{~g}$ & 7 & $184.4 \pm 8.56$ & $190.4 \pm 8.73^{* * * *}$ \\
\hline $240 \mathrm{mg} / 100 \mathrm{~g}$ & 7 & $182.3 \pm 9.05$ & $189.3 \pm 11.02$ \\
\hline
\end{tabular}

$* * \mathrm{P} \leq 0.01 * * * \mathrm{P} \leq 0.001$.

Table 2: Effects of aq. extract of $G$. spinosa on various parameters.

\begin{tabular}{|c|c|c|c|c|}
\hline \multirow{2}{*}{ Dose of drug } & Nil (control) & $40 \mathrm{mg} / 100 \mathrm{~g}$ & $120 \mathrm{mg} / 100 \mathrm{~g}$ & $240 \mathrm{mg} / 100 \mathrm{~g}$ \\
\hline & Mean \pm SE & Mean \pm SE & Mean \pm SE & Mean \pm SE \\
\hline No. of animals & 7 & 6 & 7 & 7 \\
\hline Hb $(\mathrm{g} \%)$ & $11.0 \pm 0.09$ & $10.6 \pm 0.31$ & $10.7 \pm 0.14$ & $10.6 \pm 0.13^{*}$ \\
\hline WBC (cells/cumm) & $5414.28 \pm 362.3$ & $7350 \pm 914$ & $6414.28 \pm 314.2$ & $5442.85 \pm 315.47$ \\
\hline Blood urea (mg/dl) & $23.74 \pm 1.29$ & $25.2 \pm 2.48$ & $27.12 \pm 1.88$ & $23.88 \pm 1.63$ \\
\hline Serum creatinine (mg/dl) & $0.75 \pm 0.05$ & $0.90 \pm 0.08$ & $0.72 \pm 0.07$ & $0.96 \pm 0.04^{* *}$ \\
\hline SGPT (units/l) & $25.00 \pm 1.28$ & $23.5 \pm 1.81$ & $27.13 \pm 1.54$ & $23.4 \pm 1.62$ \\
\hline S. alkaline $\mathrm{Po}_{4}$. (units/l) & $101.28 \pm 4.86$ & $90.71 \pm 4.78$ & $102.98 \pm 2.21$ & $91.6 \pm 2.70$ \\
\hline RBS (mg/dl) & $72.08 \pm 3.09$ & $103.8 \pm 9.17^{* *}$ & $72.65 \pm 2.57$ & $65.82 \pm 1.15$ \\
\hline Serum cholesterol (mg/dl) & $133.38 \pm 6.48$ & $110.8 \pm 5.82^{*}$ & $142.57 \pm 2.05$ & $129.57 \pm 2.31^{* * *}$ \\
\hline \multicolumn{5}{|l|}{ S. bilirubin (mg/dl) } \\
\hline Total & $0.71 \pm 0.02$ & $0.78 \pm 0.04$ & $0.82 \pm 0.06$ & $0.79 \pm 0.05$ \\
\hline Direct & $0.24 \pm 0.01$ & $0.21 \pm 0.02$ & $0.24 \pm 0.01$ & $0.26 \pm 0.01$ \\
\hline Indirect & $0.47 \pm 0.02$ & $0.58 \pm 0.03^{* *}$ & $0.57 \pm 0.05$ & $0.53 \pm 0.04$ \\
\hline Wt. of liver(g) & $2.68 \pm 0.15$ & $3.04 \pm 0.05$ & $2.60 \pm 0.07$ & $2.68 \pm 0.09$ \\
\hline Wt. of kidney(g) & $0.31 \pm 0.01$ & $0.31 \pm 0.03$ & $0.32 \pm 0.07$ & $0.27 \pm 0.07^{* * *}$ \\
\hline Wt. of lung(g) & $0.25 \pm 0.03$ & $0.24 \pm 0.27$ & $0.25 \pm 0.008$ & $0.23 \pm 0.01$ \\
\hline
\end{tabular}

$* \mathrm{P} \leq 0.05 * * \mathrm{P} \leq 0.01 * * * \mathrm{P} \leq 0.001$.

Table 3: Muscle co-ordinations.

\begin{tabular}{|llll|}
\hline & $\mathbf{4 0} \mathbf{~ m g} / \mathbf{1 0 0} \mathrm{g}$ & $\mathbf{1 2 0} \mathbf{~ m g} / \mathbf{1 0 0} \mathrm{g}$ & $\mathbf{2 4 0} \mathbf{~ m g} / \mathbf{1 0 0} \mathrm{g}$ \\
\hline Before treatment & Mean \pm SE & Mean \pm SE & Mean \pm SE \\
\hline $\mathbf{1}^{\text {st }}$ week & $0.83 \pm 0.31$ & $0.71 \pm 0.57$ & $0.57 \pm 0.53$ \\
\hline $\mathbf{2}^{\text {nd }}$ week & $0.48 \pm 0.09$ & $0.52 \pm 0.49^{*}$ & $0.12 \pm 0.13^{*}$ \\
\hline $\mathbf{3}^{\text {rd }}$ week & $0.22 \pm 0.09$ & $0.37 \pm 0.26$ & $0.12 \pm 0.22^{*}$ \\
\hline
\end{tabular}




\section{DISCUSSION}

When a drug is used, it is expected to benefit the recipient. At the same time, it is a fact that there is no drug, which is totally free from harmful effects. And therefore when any drug is used, it is necessary to consider not only the beneficial effect but also the harmful effects. A drug can be used only after a careful weighing, the benefit: risk ratio. When this ratio is favourable to the patient in a given situation, we can use the drug. This is true for any drug, whether it is synthetic chemical compound or a plant product. All the drugs have to pass through stringent toxicity testing, before approval can be granted for their use in general population.

In recent years there is increasing trend for using alternative system of medicine. It is argued, that such drugs are not only effective but also very safe as compared to allopathic drugs for the similar indications. The claim that natural plant product are safe should be accepted only after the plant product passes through toxicity testing using modern scientific method. ${ }^{10}$

Subacute toxicity studies in animals are of value in predicting potential toxic effects of a chemical in human beings exposed to near fatal doses. From these studies nature of sub-acute response in man may be anticipated. It also gives rough idea about the organ system involvement.

G. spinosa is habitat in the tropics and subtropics of world. Its roots, bark, fruits, milky juice, leaves have been used for medicinal purpose. ${ }^{1,2}$

In this study leaves of $G$. spinosa showed that food intake in rats was decreased, anorexiant effect might be due to feeding of 1.5 to $2.5 \mathrm{ml}$ of liquid extract during treatment. This study is not a complete study some precise study is required to assess the anorexiant effect of $G$. spinosa.

In all treated group body weight is increased after the treatment statistically significant in $40 \mathrm{mg} / 100 \mathrm{~g}$ dose and $120 \mathrm{mg} / 100 \mathrm{~g}$ dose of drug.

Blood urea and s. creatinine level were increased at higher doses weight of kidney were decreased that shows some effects on function of kidney.

Histopathological examination of kidney in all drug groups shows normal parenchyma.

De et al evaluated hepatoprotective activity of methanol extract of defatted leaves of Gymnosporia montana. After its administration, there was a significant reversal of majority of the altered biochemical parameter. Beside, a significant antagonism of the $\mathrm{CCL}_{4}$ induced changes in the liver cytoarchitecture was observed.

Our study shows that there was decrease in SGPT and increased level of $s$. bilirubin after continuous administration of drug. S. alkaline phosphatase level was significantly decreased after continuous use.

Liver weight was decreased after drug and histopathological examination of liver shows cloudy degeneration with fatty changes of liver. This is surprising finding in view of protective actions reported by De et al in $\mathrm{CCL}_{4}$ induced liver damage.

Random blood sugar was increased in rats it shows that G. Spinosa has hyperglycemic effect; it might be due to inhibition of insulin secretion or damage $\beta$ cells of pancreas. Other possible mechanism is glycogenolysis or gluconeogenesis in the liver. The use of $G$. spinosa may worsen the manifestation of diabetes.

Serum cholesterol levels were decreased in rats after continuous use of drug. On continuous administration of $G$. spinosa in people using it as a home remedy for various disorder it might produce hypocholesterolemia. Since results of these studies are inadequate to reach such conclusion further studies are required in this direction.

There was no apparent change in spontaneous motor activity.

Muscle coordination at higher dose was improved when drug was administered continuously.

This is the first study regarding the subacute toxicity of this plant as far as our knowledge goes so we were not able to compare our data with other studies. Our study has some limitations. Including chronic toxicity testing and special toxicity testing. Such aspects remain open for studies in future. Another limitation is type of extract used by us. There are studies which show the effect of methanol extract shows hepato protective activity. ${ }^{4}$

\section{CONCLUSION}

Aqueous extract of Gymnosporia spinosa did not show any lethal effect. SGPT and s. alkaline phosphatase levels were decreased, but significantly increase in s. bilirubine. Histopathological examination of liver shows cloudy degeneration in all animals of treated group and at higher dose in one animal out of seven it shows cloudy degeneration with fatty changes in liver. Renal function test shows raised the level of urea and creatinine level and decrease the weight of kidney at higher dose. Random blood sugar level was increased in study it may worsen the manifestation of diabetes.

\section{REFERENCES}

1. Mahaskar KS, Blatter E, Caius JF. Indian Medicinal plants. Allahabad; 1948: 804.

2. Kirtikar KR, Major Basu BD, Basu LM. Indian Medicinal Plants. Second edition. Allahabad; $1953 ; 3: 2327$ 
3. Nadkarni KM. Indian Materia Medica. 3rd edition. Volume 1. Bombay Popular Prakashan; 1976: 606.

4. De S, Ravishankar B, Bhavsar GC. An investigation on the hepatoprotective activity of Gymnosporia monatna. Planta Med. 1994;6(4);301.

5. Dhar ML, Dhar MM, Dhavan BN, Prasad CR, Rastogi BP, Singh KK, et al. Indian J Experimental Biol. 1973;11(1):43-54.

6. De S, Chaudhari BG, Vachharajani YR, Bhavsar. Pharmacognostic studies of Gymnosporia Montana. Int J Pharmacog. 2008;31:235-45.

7. Wilson AB. Experimental design In: Diana Anderson and conning M. Experimental toxicology university press; Cambridge: 1988.
8. Lumley CE, Walker SR. The value of chronic animal toxicology studies of pharmaceutical compounds and retrospective analysis. Fundam Appl Toxicol. 1985;5:1007-24.

9. Haywood R. Target organ toxicity. Toxicol Lett. 1981;8:349-58.

10. Jaykaran PA. Subacute toxicity study of an aqueous extract of Ficus racemosa Linn. bark in rats. J Pharm Res. 2010;3(4):814-7.

Cite this article as: Kubavat AR, Rajguru HD, Malek SM. Subacute toxicity study of an aqueous extract of dried leaves of Gymnosporia spinosa on albino rats. Int J Basic Clin Pharmacol 2020;9:48-52. 